\title{
EVALUATION OF MODIFIED ALVARADO SCORING SYSTEM IN THE DIAGNOSIS OF ACUTE APPENDICITIS
}

\author{
Syed Rizwanuddin Qazi1, Anil V. Dorakar², Varsha N. Bijwe3, Rajiv M. Mulmule ${ }^{4}$
}

${ }^{1}$ Assistant Professor, Department of General Surgery, Affiliated MUHS, Nashik University (M. S.).

${ }^{2}$ Associate Professor, Department of General Surgery, Affiliated MUHS, Nashik University (M. S.).

${ }^{3}$ Associate Professor, Department of General Surgery, Affiliated MUHS, Nashik University (M. S.).

${ }^{4}$ Associate Professor, Department of General Surgery, Affiliated MUHS, Nashik University (M. S.).

ABSTRACT
BACKGROUND
Acute appendicitis is one of the most common cause of abdominal surgical emergencies. The diagn
clinical. Despite its frequency, the diagnosis of appendicitis is sometimes difficult. Early dia
intervention is the key for successful management of acute appendicitis. In order to reduce the
various scoring systems have been developed for supporting the diagnosis of acute appendicitis. The
system is Alvarado score and equally its modifications.
Aims and Objectives-
1. To evaluate the Modified Alvarado Score System (MASS) in the diagnosis of acute appendicitis.
2. To find out sensitivity, positive and negative predictive value of MASS.
3. To find out negative appendicectomy rate.

\section{MATERIALS AND METHODS}

This is a prospective study conducted in tertiary care teaching hospital in Vidarbha from November 2016 to October 2017 . Total 196 patients were evaluated, of which 14 were excluded according to exclusion criteria. Therefore, 182 patients were included in this study.

\section{RESULTS}

182 patients were included in this study. Total 126 (67 males and 59 females) patients were operated. On histopathology, appendicitis was confirmed in 102 (58 males and 44 females) patients. Overall, sensitivity and specificity of Alvarado score was $71.57 \%$ and $45.83 \%$. Positive and negative predictive values were found to be $84.88 \%$ and $27.5 \%$ respectively. Positive appendicectomy rate was found to be $80.95 \%$. Overall, negative appendicectomy rate was $19.05 \%$.

\section{CONCLUSION}

Acute appendicitis is usually a clinical diagnosis and should remain one in the vast majority of patients coming with right iliac fossa pain. Alvarado scoring system is a very useful method to make a clinical diagnosis of acute appendicitis and can be arrived virtually in no time.

\section{KEYWORDS}

Modified Alvarado Score, Appendicitis, Right Iliac Fossa Pain.

HOW TO CITE THIS ARTICLE: Qazi SR, Darokar AV, Bijwe VN, et al. Evaluation of modified Alvarado scoring system in the diagnosis of acute appendicitis. J. Evolution Med. Dent. Sci. 2018;7(13):1648-1652, DOI: 10.14260/jemds/2018/372

\section{BACKGROUND}

Acute appendicitis is one of the most common causes of abdominal surgical emergencies. About $6 \%$ population is expected to have appendicitis in their lifetime. ${ }^{1}$ Approximately, 2 lakh appendicectomies for acute appendicitis are performed annually in USA. ${ }^{2}$

The diagnosis of acute appendicitis is clinical. Despite its frequency, the diagnoses of appendicitis is sometimes difficult. $3,4,5,6,7,8,9$

'Financial or Other Competing Interest': None.

Submission 15-02-2018, Peer Review 10-03-2018,

Acceptance 16-03-2018, Published 26-03-2018.

Corresponding Author:

Dr. Syed Rizwanuddin Qazi,

"Dilkusha" Old Bungalow,

Opposite Circuit House,

Old Bypass Road Camp,

Amravati-444602 (M.S.)

E-mail: drrizwanqazi_94@hotmail.com

DOI: $10.14260 /$ jemds $/ 2018 / 372$
A decision to operate on clinical suspicion can lead to removal of normal appendix in $15 \%-30 \%$ cases. Many surgeons advocate early surgical intervention for the treatment of acute appendicitis to avoid perforation. ${ }^{10}$ Absolute diagnosis of course is only possible at operation and histopathological examination of the specimen. ${ }^{11}$

Early diagnosis and prompt operative intervention is the key for successful management of acute appendicitis. However, the picture of acute appendicitis may not be classical and in such situation a policy of early intervention to avoid perforation may lead to high negative appendicectomy rates. 11,12

Difficulties in diagnosis arise in very young, elderly patients and females of reproductive age, because they are more likely to have an atypical presentation and many other conditions may mimic acute appendicitis in these patients. ${ }^{13}$

In such cases, clinical examination should be complimented with laparoscopy or diagnostic imaging such as ultrasound scan or CT scan to exclude diseases other than appendicitis. In spite of the advancements in medical 
diagnostics after elapse of more than a century since its first description, it continues to be a diagnostic problem and diagnostic inaccuracy in acute appendicitis has remained unchanged.

The most important diagnostic test is physical examination. The accuracy of physical examination ranges from $71 \%$ to $97 \%$ depending on the experience of the surgeon. ${ }^{14}$

In order to reduce the negative appendicectomy rate, various scoring systems have been developed for supporting the diagnosis of acute appendicitis ${ }^{15}$ and eliminate any risk of perforation, which in turn increases the rate of postoperative complication.

The most commonly used scoring system is Alvarado score and equally its modifications. ${ }^{16}$ Modified Alvarado score consisted of three symptoms, three signs and laboratory findings as described by Alvarado and later modified by Kalan et al. ${ }^{17}$

\section{Aim}

To evaluate the MASS in the diagnosis of acute appendicitis.

\section{Objectives}

1. To find out sensitivity, positive and negative predictive value of MASS

2. To find out negative appendicectomy rate.

\section{MATERIALS AND METHODS}

This is a prospective study conducted in tertiary care teaching hospital in Vidharbha from November 2016 to October 2017. Total 196 patients were evaluated, of which 14 were excluded according to exclusion criteria. Therefore, 182 patients were included in this study.

All Patients above Age 10 Years having Pain in Right Lower Abdomen were included in this Study-

\section{Study Design}

Observational Study.

\section{Study Population}

All patients with clinical diagnosis of acute appendicitis.

\section{Study Setting}

Department of Surgery of Dr. P.D.M.M.C. Amravati.

\section{Study Period}

$1^{\text {st }}$ of November 2016 to $31^{\text {st }}$ of October 2017.

\section{Sampling Method}

Convenience sampling.

\section{Data Collection Tool and Collection Method}

Patients of 10 years and above age group and both the sexes were taken into the study having right lower abdominal pain and if clinical diagnosis was acute appendicitis they were investigated and subsequently divided into the three groups according to the Alvarado scoring system.

\section{Mass: (Modified Alvarado Score System)}

\begin{tabular}{|c|c|c|}
\hline & Character & Score \\
\hline & M - Migration of pain to right iliac fossa & 1 \\
\hline \multirow[t]{3}{*}{ Symptoms } & A - Anorexia & 1 \\
\hline & $\mathrm{N}$ - Nausea/Vomiting & 1 \\
\hline & T- Tenderness in right iliac fossa & 2 \\
\hline \multirow[t]{2}{*}{ Signs } & R- Rebound tenderness & 1 \\
\hline & E- Elevated temperature & 1 \\
\hline Laboratory & L- Leukocytosis & 2 \\
\hline Investigation & S-Shift to the left of neutrophils & 1 \\
\hline
\end{tabular}

Then, further investigation in the form of pre-operative profile and USG of abdomen and pelvis was done in every patient. X-ray abdomen and X-ray KUB was done in selected cases. Scores of each patient were calculated according to MASS, then patients were divided into 3 groups.

$\begin{array}{lll}\text { Group 1 } & \text { Score 1-4 } & \text { Acute Appendicitis, unlikely } \\ \text { Group 2 } & \text { Score 5-6 } & \text { Probable } \\ \text { Group 3 } & \text { Score 7-10 } & \text { Very Probable }\end{array}$

All the patients of Group III were operated, while Group I and Group II were observed for 24 - 48 hours in the ward. Patients were further evaluated and if score system goes equal or above $(\geq) 7$ then these patients were considered for surgery.

All the specimens of excised appendix were sent for Histopathology for confirmation whether features of appendicitis were present or else. Those who responded to conservative treatment were discharged.

All data were evaluated according to the Histopathology reports that is considered as gold standard.

Approval from the Scientific Review Committee and Institutional Ethical Committee was taken before starting the study.

\section{Inclusion Criteria}

All patients above 10 years of age with clinical diagnosis of acute appendicitis.

\section{Exclusion Criteria}

1. Mass in right iliac fossa.

2. Patients with gynaecological, urological and surgical problems other than appendicitis.

3. Incomplete documentation in case sheets.

4. If not willing for Inclusion in study group.

Informed Written Consent

Was taken from all patients. 


\section{Anaesthesia}

Patients were done under general or spinal anaesthesia as per need.

\section{Surgical Procedure}

Standard conventional open surgical procedure for appendicitis.

\section{Data Entry and Statistical Analysis}

Data was entered in Microsoft Excel and was analysed in SPSS software version 16 and appropriate test of significance was applied.

\section{RESULTS}

\begin{tabular}{|c|c|c|c|}
\hline Age (In Years) & No. of Patients & Male & Female \\
\hline $11-20$ & $41(22.53 \%)$ & 24 & 17 \\
\hline$>20-30$ & $78(42.86 \%)$ & 40 & 38 \\
\hline$>30-40$ & $28(15.38 \%)$ & 15 & 13 \\
\hline$>40-50$ & $25(13.73 \%)$ & 16 & 09 \\
\hline$>50-60$ & $08(4.40 \%)$ & 05 & 03 \\
\hline$>60-70$ & $02(1.10 \%)$ & 02 & 00 \\
\hline Total & $\mathbf{1 8 2 ( 1 0 0 \% )}$ & $\mathbf{1 0 2}$ & $\mathbf{8 0}$ \\
\hline \multicolumn{4}{|l}{ Table 1. Distribution of Patients as per Age Group } \\
\hline
\end{tabular}

A total of 182 patients were included in the study, of which 102 were males (56.04\%) and 80 were females (43.96\%). Age ranged from 11 years to 69 years, mean age was 29.54 years and median was 28.0 years. Male-to-female ratio was 1.27: 1 .

\begin{tabular}{|c|c|}
\hline Alvarado Score & No. of Patients \\
\hline$\geq 7$ & $86(48 \%)$ \\
\hline $5-6$ & $72(39 \%)$ \\
\hline $1-4$ & $24(13 \%)$ \\
\hline Total & $\mathbf{1 8 2}$ \\
\hline \multicolumn{2}{|c|}{ to Alvarado 2. Distribution of Patients according } \\
\end{tabular}

\begin{tabular}{|c|c|}
\hline Alvarado Score & No. of Patients \\
\hline$\geq 7$ & 86 \\
\hline $1-6$ & 40 \\
\hline Total & $\mathbf{1 2 6}$ \\
\hline Table 3. Histopathology in Total Operated Patients \\
\hline
\end{tabular}

\begin{tabular}{|c|c|c|}
\hline $\begin{array}{c}\text { Alvarado } \\
\text { Score }\end{array}$ & $\begin{array}{c}\text { Acute Appendicitis } \\
\text { (HP +ve) }\end{array}$ & $\begin{array}{c}\text { Normal Appendix } \\
\text { (HP -ve) }\end{array}$ \\
\hline$>7(45)$ & $43[\mathrm{a}]$ & $2[\mathrm{~b}]$ \\
\hline $1-6(22)$ & $15[\mathrm{c}]$ & $7[\mathrm{~d}]$ \\
\hline \multicolumn{2}{|c|}{ Table 4. Histopathology in Operated Males } \\
\hline
\end{tabular}

\begin{tabular}{|c|c|c|}
\hline $\begin{array}{c}\text { Alvarado } \\
\text { Score }\end{array}$ & $\begin{array}{c}\text { Acute Appendicitis } \\
\text { (HP +ve) }\end{array}$ & $\begin{array}{c}\text { Normal Appendix } \\
\text { (HP -ve) }\end{array}$ \\
\hline$>7(41)$ & $30[\mathrm{a}]$ & $11[\mathrm{~b}]$ \\
\hline $1-6(18)$ & $14[\mathrm{c}]$ & $4[\mathrm{~d}]$ \\
\hline \multicolumn{2}{|c|}{ Table 5. Histopathology in Operated Females } \\
\hline
\end{tabular}

$24(13 \%)$ patients were having score within 1 - 4 range, whereas $72(39 \%)$ and $86(48 \%)$ patients were having score within 5 - 6 and 7 - 10 range respectively; 17 (70.83\%) males and 7 (29.17\%) females within 1 - 4 range; 40 (55.56\%) males and 32 (44.44\%) females in the group having score range 5 - 6; $45(52.33 \%)$ males and $41(47.67 \%)$ females in the group having score range 7 - 10 .

In males the sensitivity was found to be $74.14 \%$ and in females, sensitivity was found to be $68.18 \%$.

In males, specificity was found to be $77.78 \%$ and in females, specificity was found to be $26.67 \%$.

Overall, sensitivity and specificity of Alvarado score was $71.57 \%$ and $45.83 \%$.

Positive and negative predictive values were found to be $84.88 \%$ and $27.5 \%$ respectively.

Positive appendicectomy rate was found to be $80.95 \%$.

Negative appendicectomy rate in males is $13.44 \%$ and in females is $25.5 \%$.

Overall, negative appendicectomy rate was $19.05 \%$.

\begin{tabular}{|c|c|c|}
\hline Wound Infection & 8 & $6.35 \%$ \\
\hline Wound Dehiscence & 2 & $1.59 \%$ \\
\hline Abd. and Pelvic abscess & 0 & $0.0 \%$ \\
\hline \multicolumn{2}{|c|}{ Total } & 10 \\
\hline \multicolumn{2}{|c|}{$\begin{array}{c}\text { Table 6. Post-Operative Complications } \\
\text { (out of 126 Operated Patients) }\end{array}$} \\
\hline
\end{tabular}

\begin{tabular}{|c|c|c|}
\hline Pain in abdomen & 182 & $100 \%$ \\
\hline Migration of pain to right iliac fossa & 129 & $70.87 \%$ \\
\hline Anorexia & 92 & $50.54 \%$ \\
\hline Nausea/ Vomiting & 78 & $42.85 \%$ \\
\hline Fever & 102 & $56.04 \%$ \\
\hline Others (urinary complaint/ diarrhoea) & 07 & $03.85 \%$ \\
\hline Table 7. Showing Distribution of Clinical Symptoms and \\
Signs Symptoms \\
\hline
\end{tabular}

\begin{tabular}{|c|c|c|}
\hline Tenderness in RIF & 173 & $95.05 \%$ \\
\hline Rebound tenderness & 69 & $37.91 \%$ \\
\hline Tachycardia & 122 & $67.03 \%$ \\
\hline Temperature $>$ 37.5 & 115 & $63.19 \%$ \\
\hline \multicolumn{2}{|c|}{ Table 8. Signs } \\
\hline
\end{tabular}

\section{DISCUSSION}

In present study, we found that acute appendicitis is common in age group $>20-30$ years $(42.86 \%)$. Next group was $>10-$ 20 years $(22.53 \%)$. These findings were similar to Talukder DB et al.18

86 patients having score $7-10$ underwent appendicectomy. Acute appendicitis was confirmed after histopathology in 73 patients, of which 5 patients had perforation of appendix ( 3 males and 2 females) and 4 patients had gangrenous appendicitis $(2$ males and 2 females). 13 patients had normal appendicitis on histopathology ( 2 males and 11 females).

Out of 72 patients having score $5-6,38$ (52.76\%) underwent appendicectomy within 36 hours of admission after reassessment due to increased severity of symptoms and clinical deterioration and on revised scoring they were having score $>6 ; 11$ (7 males and 4 females) operated patients of this group showed normal appendix on histopathology.

24 patients having score of range 1 - 4 were discharged within 48 hours of admission; 2 (1 male and 1 female) patients of this group were readmitted within 36 hours of discharge with increased severity of symptoms and were found score > 6 and underwent appendicectomy. Histopathology confirmed acute appendicitis in both the patients. 
Total 126 (67 males and 59 females) patients were operated. On histopathology, appendicitis was confirmed in 102 (58 males and 44 females) patients. Positive appendicectomy rate was found to be $80.95 \%$. Negative appendicectomy rate in males was $13.44 \%$ and in females was $25.5 \%$ respectively.

In males the sensitivity and specificity were $74.14 \%$ and $77.78 \%$, whereas positive and negative predictive values were $95.16 \%$ and $31.81 \%$.

Female had sensitivity and specificity of $68.18 \%$ and $26.67 \%$ respectively. Positive and negative predictive values were $73.17 \%$ and $22.22 \%$.

Lone et al ${ }^{19}$ showed sensitivity is more in males than females.

Symptoms wise 129 (70.87\%) patients presented with migration of pain to right iliac fossa. Fever was presenting symptoms in 102 (56.04\%) patients.

On examination, tenderness in right iliac fossa was present in 173 (95.05\%) patients. However, rebound tenderness was present in 69 patients (37.91\%).

Perforation of appendices was seen in 5 patients $(2.71 \%)$ and gangrenous appendicitis was seen in 4 patients $(2.21 \%)$. Out of 24 patients in which appendix was found normal on histopathology.

11 patients had mesenteric lymphadenitis and 7 female patients had salpingitis.

Meckel's diverticulum (Wide neck) was seen in 2 patients and in 4 patients no pathology was found.

Overall, sensitivity and specificity of Alvarado score was $71.57 \%$ and $45.83 \%$ respectively and positive and negative predictive value was $84.88 \%$ and $27.5 \%$.

The results of our study are comparable with the relevant literature. Our study shows sensitivity of $71.57 \%$ comparable with the literature ranging from $67 \%$ to $93 \%{ }^{20}$ and specificity of $45.83 \%$ having range from $50 \%$ to $93 \% 20$ in the literature. The positive predictive value of $84.88 \%$ was comparable with literature reports of $97 \%,{ }^{21} 97.6 \%$ and $83.5 \% .^{22}$

We had a negative appendicectomy rate of $19.05 \%$ (males $13.44 \%$ and females $25.5 \%$ ). Similar results were reported in literature of $21 \%, 15.6 \%{ }^{22}$ and $7 \% .{ }^{21}$

There are even opinions and evidences that if negative appendicectomy rates are below $10 \%-15 \%$ the surgeon is operating on too few patients on clinical ground, thus increasing the risk of complications. ${ }^{23}$

Wound infection rate was $6.35 \%$ (8 patients). Wound dehiscence was seen in two patients (1.59\%). Postoperatively, no patient showed abdominal and pelvic abscess.

Despite the availability of radiological (US/CT) investigative modalities, a recent population based study in USA indicated that there was essentially no change in the frequency of negative appendicectomy. ${ }^{24}$

Similar results were also reported, where the authors found USG did not have any additional benefit over Alvarado score and were of the opinion that USG is unnecessary in diagnosis of acute appendicitis. 25

\section{CONCLUSION}

Acute appendicitis is usually a clinical diagnosis and should remain one in the vast majority of patients coming with right iliac fossa pain. Alvarado scoring system is a very useful method to make a clinical diagnosis of acute appendicitis and can be arrived virtually in no time. It is simple, extremely cost effective and useful in even the remotest of geographies in the majority of patients of acute appendicitis.

\section{REFERENCES}

[1] HES Online. http://www.hesonline.nhs.uk.

[2] Sim KT, Picone S, Crade M, et al. Ultrasound with graded compression in the evaluation of acute appendicitis. J Natl Med Assoc 1989;81(9):954-7.

[3] Kosloske AM, Love CL, Rohrer JE, et al. The diagnosis of appendicitis in children: outcomes of a strategy based on pediatric surgical evaluation. Pediatrics 2004;113(1 Pt 1):29-34.

[4] Pena BM, Taylor GA, Fishman SJ, et al. Effect of an imaging protocol on clinical outcomes among pediatric patients with appendicitis. Pediatrics 2002;110(6):1088-93.

[5] Wang LT, Prentiss KA, Simon JZ, et al. The use of white blood cell count and left shift in the diagnosis of appendicitis in children. Pediatr Emerg Care 2007;23(2):69-76.

[6] Kessler N, Cyteval C, Gallix B, et al. Appendicitis: evaluation of sensitivity, specificity and predictive values of US, Doppler US and laboratory findings. Radiology 2004;230(2):472-8.

[7] Sack U, Biereder B, Elouahidi T, et al. Diagnostic value of blood inflammatory markers for detection of acute appendicitis in children. BMC Surg 2006;6:15.

[8] Hardin DM. Acute appendicitis: review and update. Am Fam Physician 1999;60(7):2027-34.

[9] Nance ML, Adamson WT, Hedrick HL. Appendicitis in the young child: a continuing diagnostic challenge. Pediatr Emerg Care 2000;16(3):160-2.

[10] Kalan M, Talbot D, Cunliffe WJ, et al. Evaluation of the modified Alvarado score in the diagnosis of acute appendicitis: a prospective study. Ann R Coll Surg 1994;76(6):418-9.

[11] Dado G, Anania G, Baccarani U, et al. Application of a clinical score for the diagnosis of acute appendicitis in childhood: a tetrospective analysis of 197 patients. J Pediatr Surg 2000;35(9):1320-2.

[12] Paulson EK, Kalady MF, Pappas TN. Clinical practice. Suspected appendicitis. N Eng J Med 2003;348(3):23642.

[13] Gilmore OJ, Browett JP, Griffin PH, et al. Appendicitis and mimicking conditions. Lancet 1975;306 (7932):421-4.

[14] Fung HS, Lau S, Siu JCW, et al. Audit of ultrasonography for diagnosis of acute appendicitis: a retrospective study. J HK Coll Radiol 2008;11:108-11.

[15] Ohmann C, Franke C, Yang Q. Clinical benefit of diagnostic score for appendicitis: results of a prospective interventional study. German Study Group of Acute Abdominal Pain. Arch Surg 1999;134(9): 993-6.

[16] Chan MY, Teo BS, Ng BL. The Alvarado score and acute appendicitis. Annals of The Academy of Medicine Singapore 2001;30(5):510-2.

[17] Alvarado A. Apractical score for the early diagnosis of acute appendicitis. Ann Emerg Med 1986;15(5):55764. 


\section{Jemds.com}

[18] Talukder DB, Siddiq AKMZ. Modified Alvarado scoring system in the diagnosis of acute appendicitis. JAFMC Bangladesh 2009;5(1):18-20.

[19] Lone NA, Shah M, Wani KA, et al. Modified Alvarado score in diagnosis of acute appendicitis. Indian Journal for the Practicing Doctor 2006;3:1-4.

[20] Anurag, Rao S, Gupta D, et al. Modified Alvarado scoring system as a diagnostic tool in a Central Indian rural hospital. IJHSR 2017;7(7):38-44.

[21] Jawaid A, Asad A, Motiei A, et al. Clinical scoring system: a valuable tool for decision making in cases of acute appendicitis. J Pak Med Assoc 1999;49(10): 254-9.

\section{Original Research Article}

[22] Khan I, Ur Rehman A. Application of Alvarado scoring in diagnosis of acute appendicitis. J Ayub Med Coll Abbottabad 2005;17(3):41-4.

[23] Ohmann C, Yang Q, Franke C. Diagnostic scores for acute appendicitis. The Abdominal Pain Study Group. Eur J Surg 1995;161(4):273-81.

[24] Abdeldaim Y, Mahmood S, McAvinchey D. The Alvarado score as a tool for diagnosis of acute appendicitis. Ir Med J 2007;100(1):342.

[25] Baidya N, Rodrigues G, Rao A, et al. Evaluation of Alvarado score in acute appendicitis: a prospective study. The Internet J Surg 2007;9:1. 